\title{
Association Between Adverse Childhood Experiences, Resilience and Mental Health in a Hispanic Community
}

\author{
Maribel G. Dominguez ${ }^{1}\left[\right.$ [ Louis D. Brown ${ }^{2}$ (])
}

Accepted: 7 January 2022 / Published online: 22 January 2022

This is a U.S. government work and not under copyright protection in the U.S.; foreign copyright protection may apply 2022

\begin{abstract}
This study explores the relations between adverse childhood experiences (ACEs), mental health and resilience among Hispanic adults living in the United States - Mexico Border region. Numerous studies have investigated the negative impact of ACEs on adult mental health, but the concept of resilience as a protective factor for mental health in the Hispanic communities has limited consideration in ACE treatment interventions. The proposed study addresses this gap in knowledge by investigating relations between ACEs, resilience, and mental health. An online survey was administered to 221 university students to assess the relationship between ACEs, mental distress and resilience. Using hierarchical linear regression, three models were estimated. First, including demographics, second including ACEs and low resilience, followed by the interaction of ACEs and resilience. Analyses indicate that ACEs were associated with mental distress $(\mathrm{B}=1.02,95 \%$ CI $0.37-1.68$, $p<0.01)$ and low resilience was associated with mental distress $(\mathrm{B}=5.37,95 \%$ CI $3.15-7.59, p<.01)$. The interaction between ACEs and low resilience was also related to mental distress $(\mathrm{B}=1.32,95 \% \mathrm{CI} 0.17-2.47, p=0.03)$, indicating that ACEs had a larger association with mental distress among respondents with low resilience. Findings highlight the importance of the direct association between resilience and mental distress, along with the moderating influence of resilience on the relation between ACEs and mental health. Interventions promoting resilience may be effective in reducing mental distress, especially among individuals with a history of ACEs.
\end{abstract}

Keywords Adverse childhood experiences (ACE) $\cdot$ Mental distress $\cdot$ Resilience $\cdot$ Stressful life events $\cdot$ Trauma

Extensive research demonstrates that individuals exposed to ACEs present higher rates of anxiety, depression, and suicide attempts, among other mental and physical health issues (Agorastos et al., 2014; Chang et al., 2019; Edward, 2003; Karatekin, 2018). Resilience is a promising protective factor that may help reduce the influence of ACEs on mental health by helping individuals overcome adversity (Hamby et al., 2018; Ungar, 2013; Venta et al., 2019). Yet little empirical work investigates the relationship between ACEs, mental health and resilience, in Hispanic communities (Newcomb et al., 2003; Merino et al., 2017). This study seeks to fill this gap in the literature by examining

Maribel G. Dominguez

maribeldominguezcontact@gmail.com

1 Department of Public Health, University of Texas at El Paso, P.O. Box 960581, El Paso, Texas 79996, USA

2 Department of Health Promotion and Behavioral Sciences, School of Public Health in El Paso, The University of Texas Health Science Center at Houston, Texas, US the relationship between ACEs, mental distress, and resilience among adults in a unique and predominantly Hispanic population on the U.S.-Mexico border.

\section{Adverse Childhood Experiences (ACEs)}

ACEs include psychological, physical, and sexual abuse, neglect and household dysfunction including domestic violence, divorce, parental incarceration and substance abuse (Felitti et al., 1998). One explanation for the impact ACEs have on health is through neurodevelopmental changes (Brown et al., 2013; Navalta et al., 2018). A child exposed to toxic stress may experience unusual wear and tear on their neurophysiological regulation state (Sciaraffa et al., 2018). The child's vulnerability to developing biological, psychological, behavioral and mental health issues in adulthood has then increased, specifically because they are at a vulnerable developmental stage (Johnson et al., 2013). 
A dose-response relationship was found between ACE's and the leading causes of death in the United States (Felitti et al., 1998). At least six in ten people in the general population have been exposed to at least one type of ACE (Brown et al., 2013). ACE prevalence recorded by 23 U.S. States using the Behavioral Risk Factor Surveillance System from $2011-2014$ was $15.8 \%$ for exposure to four or more ACEs, and $45.7 \%$ for exposure to one or more ACEs (Merrick et al., 2018).

\section{ACEs, Mental Health and Mental Distress}

Mental health is defined as the state of wellbeing where an individual is able to cope effectively with normal stresses, work productively and contribute to their own community while realizing their own potential (WHO, 2004). In contrast to mental health, mental distress causes pathological symptoms and diagnoses that range in severity and that may have lifelong impacts on health and disease risk (Hammarström, 2016; Prince et al., 2016). Mental distress is a concept used to define a painful set of mental symptoms that affect the normal state of mood in individuals (American Psychological Association, 2020).

ACEs have been associated with the development of psychiatric disorders (Elkins et al., 2019). For example, Agorastos et al., (2014) found that having a single ACE was a risk factor for the development of depression (OR: 2.2, 95\% CI: 1.3-3.8). A dose-response relationship between ACE scores and depressive disorders has also been documented, with a $23 \%$ lifetime prevalence of depressive disorders among individuals experiencing one or more ACEs (Mersky et al., 2013; Poole et al., 2017). Further, the consequences of ACEs may be more severe in Hispanic communities, as previous research found larger associations between ACEs and chronic disease among Hispanic relative to non - Hispanic adolescents (Elkins et al., 2019). Other studies have shown that Hispanic respondents present higher ACEs and higher levels of mental distress, less peace, and more nervousness (Barrera et al., 2019; La Brenz et al., 2020; Zetino et al. (2020).

\section{Resilience as a Protective factor}

This study conceptualizes resilience as a personal quality that allows someone to overcome adversity, through the use of internal resources such as self-esteem, strength, humor, problem solving, stress management, and adaptability to change (Connor \& Davidson, 2003). We do not include in our conceptualization of resilience external resources that may also help an individual cope with adversity. We focus on resilience as an internal resource because it may differentiate between the success of individuals facing similarly challenging external circumstances in an under-resourced Hispanic community. Resilient coping processes serve as a protective strategy following adverse events and are associated with positive development under stress (Forbes et al., 2018; Spencer-Hwang et al., 2018; Ungar \& Liebenberg, 2011). These internal characteristics are changeable and previous research suggests they can be cultivated (Martel et al., 2007; Nurius et al., 2020a, b). Interventions addressing resilience have improved personal confidence, socials skills and selfefficacy (Bray \& Swann, 2018; Mackay et al., 2017).

Although our conceptualization of resilience is widespread in the literature, previous studies on ACEs, resilience, and mental health have varied in their operationalization of resilience. Specifically, one study found that the association between ACEs and adult mental distress was substantially weaker among individuals who always had a trusted adult available as a child (Bellis et al., 2017). Another study found the association between ACEs and poor mental health was lower among individuals with the resilience resources of adequate sleep, social support, and life satisfaction (Logan - Greene et al., 2014). Thus, previous research suggests resilience moderates the relationship between ACEs and mental distress, but it remains unclear how the operationalization of resilience may impact its moderating effect.

Furthermore, there is no literature to our knowledge exploring the role of resilience in understanding relations between ACEs and mental health in Hispanic communities such as the U.S.-Mexico border region. Understanding resilience as it relates to ACEs and mental health can contribute to the development of trauma informed interventions building resilience as a modifiable protective factor to help alleviate the effects of ACEs (Logan - Greene et al., 2014; Purewal et al., 2016). Disparities in the provision of mental health care are particularly severe for vulnerable Hispanic populations (Liu et al., 2020; Venta et al., 2019; Villalobos $\&$ Bridges, 2018). The high rates of poverty and limited access to health insurance inhibit access to mental health treatment (Caballero et al., 2017). This study may inform the development of resilience-building interventions, a potentially cost-effective strategy for alleviating the deleterious effects of ACEs in Hispanic communities.

\section{The Present Study}

Although extensive literature links ACEs with mental health, it is unclear how the resilience of individuals exposed to ACEs may alter the connection between ACEs and mental health, especially in Hispanic communities. Thus, the goal of this study is to examine relations between ACEs, mental 
Fig. 1 Conceptual Framework

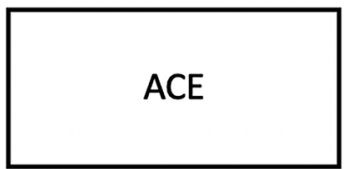

health, and resilience in a Hispanic community. Based on previous research, our conceptual framework (see Fig. 1) describes how ACEs prevent individuals from having optimal health, and how resilience can play a protective role against the development of poor mental health.

The aim of the study is to test this conceptual model based on the following hypotheses:

1. ACEs are positively related to mental distress

2. Resilience is negatively associated with mental distress

3. The positive relation between ACEs and mental distress only exists in the lower resilience population.

\section{Methods}

This study was reviewed and approved by the University of Texas at El Paso Institutional Review Board on March $12,2019$.

\section{Participants}

Participants were English and Spanish speaking students from the University of Texas at El Paso, an institution with an 80\% Hispanic population (UTEP CIERP, 2018). A total of 221 participants answered the survey. Inclusion criteria required for participants to be current students and be at least 18 years of age. Students from all degree programs including undergraduate and graduate were allowed to participate. A target sample size of 220 was determined through an a priori power analysis, which allowed us to detect a population correlation of 0.2 with a power of 0.08 with a $p$ value of 0.05 (Cohen, 1988).

\section{Procedures}

A 15-min-long anonymous electronic survey was administered to participants using the Question Pro Platform. The
ACE, Resilience \& Mental Distress

Fig. 1 Conceptual Model

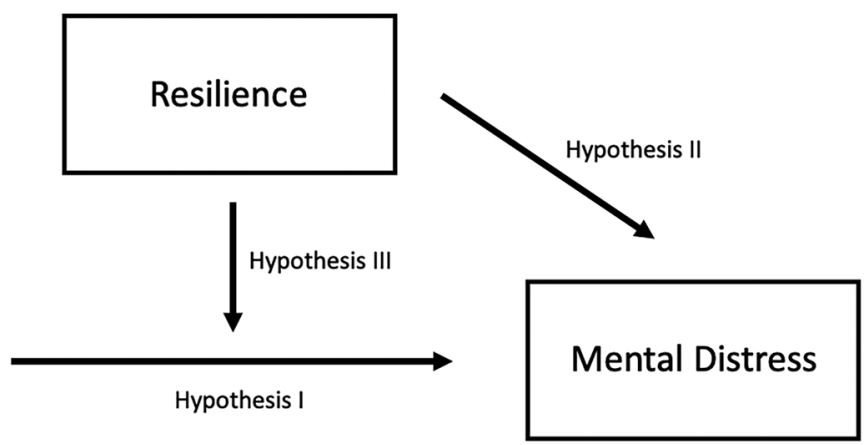

survey had an initial landing page that included the consent form, once participants agreed to participate the electronic survey would commence, An opportunistic sampling technique was used for recruitment. The recruitment strategy was to distribute wallet size flyers in both English and Spanish with a QR code and concise instructions that directed participants to the survey. Flyers were distributed after three undergraduate classroom announcements along with two visits to the student union, four visits to the library, and four visits to the student food court.

\section{Measures}

This study used a quantitative cross-sectional design. A survey was assembled with scales that measured each of the three main constructs, along with sociodemographic characteristics and past year threatening events. The study questionnaire was constructed from valid and reliable measures of ACEs, mental distress and resilience in both English and Spanish (Labrenz et al., 2019; Soler Sánchez et al., 2016; Zhang et al., 2012).

\section{Demographic}

Demographic questions detailed in Table 1, assessed age, biological sex, Hispanic or Latino origin, race/ethnicity, employment level, income, marital status, place of birth and education status.

\section{Adverse Childhood Experiences (ACE) Questionnaire}

The ACE questionnaire is a 10-item scale developed by researchers from the Kaiser Permanente's San Diego Health Appraisal Clinic and the CDC (Felitti et al., 1998). The questionnaire assessed childhood adversity and includes exposures to household dysfunction, neglect, physical, sexual and emotional abuse (Felitti et al., 1998). Following Felitti et al. 
Table 1 Demographic Information

\begin{tabular}{|c|c|c|c|c|c|}
\hline \multicolumn{2}{|l|}{ Characteristics } & \multirow{2}{*}{$\begin{array}{l}\mathrm{N} \\
221\end{array}$} & \multirow[t]{2}{*}{$\%$} & \multirow[t]{2}{*}{ Mean } & \multirow[t]{2}{*}{ SD } \\
\hline Sample Size & & & & & \\
\hline \multirow[t]{2}{*}{ Biological Sex } & Female & 147 & 66.5 & 1.67 & 0.47 \\
\hline & Male & 74 & 33.5 & & \\
\hline \multirow[t]{2}{*}{ Place of Birth } & Not U.S. Born & 62 & 28.1 & 0.72 & 0.45 \\
\hline & U.S. Born & 159 & 71.9 & & \\
\hline \multirow[t]{2}{*}{ Ethnicity } & Non-Hispanic & 48 & 21.7 & 0.78 & 0.41 \\
\hline & Hispanic & 173 & 78.3 & & \\
\hline \multirow[t]{3}{*}{ Employment } & Not Employed & 29 & 13.1 & 1.56 & 1.61 \\
\hline & Employed & 154 & 69.7 & & \\
\hline & No Response & 38 & 17.2 & & \\
\hline \multirow[t]{5}{*}{ Income } & Less than 20,000 & 175 & 79.2 & 1.3 & 0.71 \\
\hline & 20,000 to 40,000 & 28 & 12.7 & & \\
\hline & 40,000 to 60000 & 11 & 5 & & \\
\hline & 60,000 to 70,000 & 1 & 0.5 & & \\
\hline & 70,000 or more & 3 & 1.4 & & \\
\hline \multirow[t]{2}{*}{ Marital Status } & Married & 12 & 5.4 & 1.95 & 0.23 \\
\hline & Not Married & 209 & 94.6 & & \\
\hline \multirow[t]{5}{*}{ Education } & High school graduate & 31 & 14 & 3.13 & 0.72 \\
\hline & Some college & 141 & 63.8 & & \\
\hline & Bachelor's Degree & 42 & 19 & & \\
\hline & Master Degree & 4 & 1.8 & & \\
\hline & Doctorate Degree & 3 & 1.4 & & \\
\hline
\end{tabular}

(1998), the total ACE score was computed by summing the "yes" responses to childhood exposures.

\section{Connor-Davidson Resilience Scale (CD-RISC 10)}

The scale measures resilience as the ability to thrive in the face of adversity, assessing self-esteem strength, humor, problem solving, successfully coping with stress, and adaptability to change (Connor \& Davidson, 2003). The CD - RISC scale is widely utilized because of its validity and reliability in different countries and languages (Connor \& Davidson, 2003). The CD-RISC is a 10 item Likert scale, with answer options "Not True at all", "Rarely True", "Sometimes True", "Often True" and "True nearly all the time." A higher score represented higher resilience levels. In this study the scale had a good internal consistency $(\alpha=0.86)$.

\section{Kessler Psychological Distress Scale (K10)}

The Kessler Psychological Distress Scale (K10) is a 10-item questionnaire measuring psychological distress based on questions regarding symptoms of anxiety and depression (Prochaska et al., 2012). The K10 is a widely used and well validated scale that assesses the psychological distress among clinical and general populations (Cronbach alpha $=0.88$ ) (Easton et al., 2017). The K10 scale has a fivelevel response scale, "All of the time", "Most of the time", "Some of the time", "A little of the time" and "None of the time" with a range of a low 10 to a high 50 (Kessler et al., 2003). The scale demonstrated high reliability in this study $(\alpha=0.93)$.

\section{Past Year Threatening Events}

To differentiate ACEs from more recent adverse experiences, we assessed past year threatening events with the List of Threatening Experiences (LTE) scale. This 12-item scale developed by Motrico et al. (2013) has high sensitivity and reliability (Kappa range $=0.61-0.87$ ). Each item depicts a life event that has been identified as inducing stressful psychological experiences. The scale included the main question "Has any of the following events have occurred to you in the last 6 months?" related to various responses including financial crisis, serious illness or relationship problems. Each yes response to an LTE accounted for a value of 1, with scores ranging from $0-12$. Internal consistency was modest, which is typical of count measures $(\alpha=0.60)$.

\section{Data Analyses}

In order to test all three hypotheses, we used hierarchical linear regression, with mental distress as the dependent variable. In the first model, we entered the demographic characteristics and past year threatening events, which served as covariates in our model. In the second model we tested the first and second hypotheses by adding ACEs and resilience to the model. In the third model we tested the third hypotheses by adding the ACEs $\mathrm{x}$ resilience interaction term to the model. All analyses were conducted using IBM SPSS Statistics 25. We also analyzed the data with nonHispanics excluded, reaching identical conclusions on our hypothesis tests. We report findings from only the full sample because it offers more precise estimates of the relations under investigation.

\section{Results}

\section{Sample Demographics}

A total of 221 participants completed the survey, with all participants completing all survey items under investigation. Table 1 reports the demographic characteristics of participants in detail. Respondents were $67 \%$ female, with $72 \%$ born in the United States, 78\% of Hispanic descent, and $80 \%$ with yearly incomes of less than $\$ 20,000$. The survey 
was available in English and Spanish $89.7 \%$ of participants took the English version and thus $10.3 \%$ the Spanish version.

Table 2 presents the covariates and model tested hierarchical regression model. Step one of the hierarchical regression model predicting mental distress entered these sociodemographic covariates, along with past year threating events. The only significant sociodemographic characteristic was being U.S. born, which was associated with higher mental distress $(\mathrm{B}=2.75,[0.01,5.40], p=0.05)$. Past year threatening events also had a significant and positive association with mental distress $(\mathrm{B}=1.87,[1.16,2.64], p<0.01)$. All covariates together accounted for $15.2 \%$ of the variance in mental distress.

\section{Hypothesis Tests}

\section{Hypothesis 1: ACE's are Positively Related to Mental Distress}

Our first hypothesis was tested in model 2. ACEs were positively associated with mental distress, consistent with our first hypothesis $(\mathrm{B}=1.02,[0.37,1.68], p<0.01)$. An increase of one standard deviation in ACEs, predicted a 0.21 standard deviation increase in mental distress. Model 2 included ACEs and low resilience, accounting for $26.4 \%$ of the variance in mental distress, as compared to $15.2 \%$ in model 1 , which just had the covariates.
Table 2 Regression models predicting Mental Distress with Demographic Characteristics, Past Year Threatening Events (LTE), Adverse Childhood Experiences (ACEs), Low Resilience, and ACEs $\mathrm{x}$ Resilience

\begin{tabular}{|c|c|c|c|c|c|c|c|}
\hline Model 1 & B & $95 \% \mathrm{CI}$ & $\boldsymbol{\beta}$ & $95 \% \mathrm{CI}$ & Sig & $\boldsymbol{R}^{2}$ & $\Delta R^{2}$ \\
\hline Intercept & 14.02 & {$[2.74,29.46]$} & & & 0.08 & 0.39 & 0.15 \\
\hline Gender $^{1}$ & 1.00 & {$[-1.48,3.48]$} & 0.05 & {$[-0.08,0.18]$} & 0.43 & & \\
\hline Place of Birth ${ }^{2}$ & 2.75 & {$[0.1,5.40]$} & 0.13 & {$[0.01,0.27]$} & 0.04 & & \\
\hline Ethnicity $^{3}$ & -0.18 & {$[-3.09,2.74]$} & -0.01 & {$[-0.14,0.12]$} & 0.91 & & \\
\hline Employment $^{4}$ & -0.55 & {$[-1.29,0.20]$} & -0.09 & {$[-0.23,0.04]$} & 0.15 & & \\
\hline Income $^{5}$ & 0.04 & {$[-1.73,1.79]$} & 0.00 & {$[-0.13,0.14]$} & 0.97 & & \\
\hline Marital Status $^{6}$ & 0.59 & {$[-5.33,6.50]$} & 0.02 & {$[-0.13,0.16]$} & 0.85 & & \\
\hline Education ${ }^{7}$ & 1.04 & {$[-0.77,2.86]$} & 0.08 & {$[-0.06,0.22]$} & 0.26 & & \\
\hline Past Year Threatening Events & 1.87 & {$[1.16,2.59]$} & 0.34 & {$[0.21,0.47]$} & $<0.01$ & & \\
\hline Model 2 & & & & & & 0.51 & 0.11 \\
\hline Intercept & 7.75 & {$[-6.86,22.37]$} & & & 0.30 & & \\
\hline Gender $^{1}$ & 0.88 & {$[-1.44,3.20]$} & 0.05 & {$[-0.08,0.17]$} & 0.46 & & \\
\hline Place of Birth ${ }^{2}$ & 3.55 & {$[1.05,6.05]$} & 0.17 & {$[0.05,0.30]$} & 0.01 & & \\
\hline Ethnicity $^{3}$ & -0.21 & {$[-2.94,2.52]$} & -0.01 & {$[-0.13,0.11]$} & 0.88 & & \\
\hline Employment ${ }^{4}$ & -0.41 & {$[-1.11,0.29]$} & -0.07 & {$[-0.19,0.05]$} & 0.25 & & \\
\hline Income $^{5}$ & 0.13 & {$[-1.53,1.80]$} & 0.01 & {$[-0.12,0.14]$} & 0.88 & & \\
\hline Marital Status $^{6}$ & 1.92 & {$[-3.64,7.48]$} & 0.05 & {$[-0.09,0.19]$} & 0.50 & & \\
\hline Education $^{7}$ & 1.02 & {$[-0.68,2.72]$} & 0.08 & {$[-0.05,0.21]$} & 0.24 & & \\
\hline Past Year Threatening Events & 1.29 & {$[0.55,2.03]$} & 0.23 & {$[0.1,0.37]$} & $<0.01$ & & \\
\hline Adverse Childhood Experiences (ACEs) & 1.02 & {$[0.37,1.68]$} & 0.21 & {$[0.08,0.35]$} & $<0.01$ & & \\
\hline Low Resilience & 5.37 & {$[3.15,7.59]$} & 0.29 & {$[0.17,0.41]$} & $<0.01$ & & \\
\hline Model 3 & & & & & & 0.53 & 0.18 \\
\hline Intercept & 10.80 & {$[-3.92,25.51]$} & & & 0.15 & & \\
\hline Gender $^{1}$ & 0.51 & {$[-1.81,2.83]$} & 0.03 & {$[-0.09,0.15]$} & 0.67 & & \\
\hline Place of Birth ${ }^{2}$ & 3.81 & {$[1.32,6.29]$} & 0.19 & {$[0.07,0.31]$} & $<0.01$ & & \\
\hline Ethnicity $^{3}$ & -0.25 & {$[-2.95,2.46]$} & -0.01 & {$[-0.13,0.11]$} & 0.86 & & \\
\hline Employment $^{4}$ & -0.37 & {$[-1.06,0.32]$} & -0.06 & {$[-0.19,0.06]$} & 0.29 & & \\
\hline Income $^{5}$ & 0.09 & {$[-1.56,1.74]$} & 0.01 & {$[-0.12,0.14]$} & 0.92 & & \\
\hline Marital Status $^{6}$ & 1.27 & {$[-4.27,6.80]$} & 0.03 & {$[-0.11,0.17]$} & 0.65 & & \\
\hline Education $^{7}$ & 0.94 & {$[-0.75,2.63]$} & 0.07 & {$[-0.06,0.21]$} & 0.27 & & \\
\hline Past Year Threatening Events & 1.19 & {$[0.45,1.93]$} & 0.21 & {$[0.08,0.35]$} & $<0.01$ & & \\
\hline Adverse Childhood Experiences (ACEs) & 0.48 & {$[-0.32,1.28]$} & 0.10 & {$[-0.07,0.27]$} & 0.23 & & \\
\hline Low Resilience & 3.11 & {$[0.16,6.07]$} & 0.17 & {$[0.01,0.33]$} & 0.04 & & \\
\hline ACEs x Low Resilience & 1.32 & {$[0.17,2.47]$} & 0.22 & {$[0.03,0.41]$} & $\mathbf{0 . 0 3}$ & & \\
\hline
\end{tabular}

${ }^{1}$ Male $=1$, Female 2; ${ }^{2}$ Not-U.S. Born $=0$, U.S. Born $=1$; ${ }^{3}$ Non-Hispanic $=0$, Hispanic $=1$; ${ }^{4}$ Not Employed $=0$, Employed $=1 ;{ }^{5} 20,000$ or less $=1,20,000-40,000=2,40,000-60,000=3,60,000-$ $70,000=4,70,000$ or more $=5 ;{ }^{6}$ Not Married $=0$, Married $=1 ;{ }^{7}$ No High School=1, High School=2, Some College $=3$, Bachelors $=4$, Masters $=5$, Doctorate $=6$ 


\section{Hypothesis 2: Resilience is Negatively Associated with Mental Distress}

Consistent with our second hypothesis, mental distress was associated with low resilience $(\mathrm{B}=5.37$ [3.14, 7.60], $p<0.01)$. Low resilience was determined by the calculation of scores less than or equal to 29 total points. The model predicted 0.29 standard deviation increase in mental distress for respondents with low resilience $(\mathrm{CI}=[0.17,0.41], p<0.01)$.

\section{Hypothesis 3: The Positive Relation Between ACEs and Mental Distress only Exists in the Lower Resilience Population}

As illustrated by Fig. 2, the results from our third model were also consistent with our third hypothesis; the ACEs $\mathrm{x}$ Low Resilience interaction term was significantly and positively associated with mental distress $(\mathrm{B}=1.32,[0.17$, 2.47], $p=0.03$ ). Thus, among low resilience participants (but not high resilience participants), a one standard deviation increases in ACEs predicted a 0.23 standard deviation increase in mental distress. Further, the relation between ACEs and mental distress independent of resilience status decreased from $\mathrm{B}=1.02([0.37,1.68], p<0.01)$ in Model 2 to a non-significant value of $\mathrm{B}=0.48([-0.32,1.28], p=0.23)$ in Model 3, due to the addition of the ACEs x Low Resilience interaction term. The third and final model accounted for $28.2 \%$ of the variance of mental distress $\left(\mathrm{R}^{2}=0.28\right)$, relative to $26.4 \%$ of the variance in model 2 .

\section{Discussion}

This study examined the understudied role of resilience in understanding the relation between ACEs and mental distress in a Hispanic community. Each of the three core

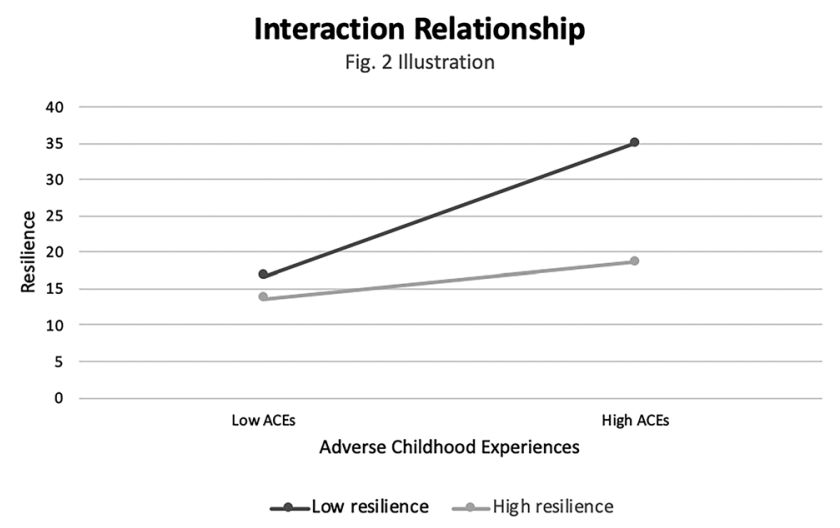

Fig. 2 Interaction Relationship: Adverse Childhood Experiences (ACEs) and Resilience hypotheses were supported by our findings. Specifically, ACEs and resilience were related to mental distress, with resilience moderating the relation between ACEs and mental distress. These findings highlight the importance of cultivating resilience to mitigate the influence of ACEs on mental distress. We consider the implications of each of the three core hypotheses in more detail here.

Our first hypothesis, that ACEs are positively associated with mental distress, was supported by our data and previous research (Bellis et al., 2017; Easton, 2017; Felitti et al., 1998; Manyema et al., 2018; Martín-Blanco et al., 2016; Logan - Greene et al., 2014). The association between ACEs and mental distress may follow from neurophysiological dysregulations created by ACEs, which operate as stressors that dysregulate a child's development. As a consequence, adverse experiences create cognitive, social, physical, behavioral and mental challenges linked to chronic diseases and risk behaviors (Felitti et al., 1998; Gilbert et al., 2015). Based on this finding it is not only important to prevent ACEs but also to help people recover from their effects, as research demonstrates that the impact of ACEs on adult mental health are severe and long-lasting (Felitti et al., 1998).

Our second hypothesis, that mental distress is associated with low resilience, was also supported by our findings. Consistent with previous research, resilience plays a protective role in mental health. Literature suggests that resilience can help people overcome the effects of life adversities and regulate mental health symptoms, thereby promoting psychological endurance (Banyard et al., 2017; Rutten et al., 2013). Thus, higher rates of resilience have been associated with less disability, better self-reported health, emotional equilibrium, and improved quality of life (Robottom et al., 2011). Due to the role that resilience plays in overcoming adversity, promoting resilience can help improve mental health and thus alleviate the effects of ACEs, allowing for a better quality of life after adversity. Research suggests resilience is a changeable target for interventions, as strategies that enhance resilience are emerging (Bray \& Swann, 2018; Mackay et al., 2017; Martel et al., 2007; Nurius et al., 2020a, b).

The third hypothesis, that the relation between ACEs and mental distress only exists in the lower resilience population, was also supported. These findings are consistent with previous research (Bellis et al., 2017; Logan Greene et al., 2014) but unique in that resilience is defined more broadly in the current study. The current study utilized a self-rated resilience scale with reliable psychometric properties that allowed participants to select their own degree of agreement with each resilience item. Our findings highlight the importance of resilience in mitigating the severe consequences of ACEs on health and well-being. Given the prevalence of ACEs in our society, the cultivation of 
resilience may provide substantial health benefits. The basis of this finding lies in early life experiences, which set the path for adult mental health, with resilience helping people cope with early life adversity (as illustrated in Fig. 1).

In comparison to previous ACE studies, our study worked with a sample of predominantly Hispanic (78\%) individuals of which $80 \%$ were low-income status. As reported in Table 3, participants reported relatively high rates of ACES, with $16 \%$ reporting exposure to four or more ACEs and $67 \%$ reporting at least one ACE. In comparison, the Felitti et al. (1998) landmark ACE study with 8,056 predominately Caucasian $(79 \%)$ college graduates $(43 \%)$, had $52 \%$ reporting at least one ACE, with $6.2 \%$ reporting more four or more ACEs. Similarly, Bellis et al. (2017) had a sample of 7,047 participants (85\% Caucasian) and $10 \%$ of their sample had four or more ACEs. Gilbert and colleagues (2015) presented a large sample size of 53,998 in the District of Columbia ( $80 \%$ Caucasian, $38 \%$ college graduates), $12.7 \%$ reported to having more than four ACEs.

Additionally, findings identified potential risk factors for mental distress among Hispanic. The first is the association between being U.S born and higher mental distress. This finding is consistent with previous research, which identified higher rates of mental distress among U.S. born Hispanic and higher rates of ACEs (Caballero et al., 2017). Mental distress among U.S. born Hispanic may be due to challenges related to parental immigration status, acculturation processes, and acculturative stress (Katiria et al., 2014; Rojas-Flores et al., 2017). The second risk factor is past year threatening events, which were positively associated with mental distress. Interestingly, previous literature links parental immigration status with threatening events for Hispanic individuals, which may contribute to both depression and anxiety (Caplan et al., 2012; Chavez-Dueña et al., 2019).

Table 3 ACE Scores

\begin{tabular}{lllll}
\hline \# of ACEs & N & \% & M & SD \\
\hline 0 & 73 & 33 & 1.72 & 1.91 \\
1 & 58 & 26.2 & & \\
2 & 30 & 13.6 & & \\
3 & 24 & 10.9 & & \\
4 & 12 & 5.4 & & \\
5 & 10 & 4.5 & & \\
6 & 8 & 3.6 & & \\
7 & 3 & 1.4 & & \\
8 & 3 & 1.4 & & \\
Total & 221 & 100 & & \\
\hline
\end{tabular}

This table represents the frequencies of ACE scores. N, \%, M, SD represent total count, percent, mean and standard deviation, respectively

\section{Strengths and Limitations}

Our study demonstrated several strengths. First, this study was conducted on an a priori basis, with hypotheses developed first, followed by a power analysis, data collection and planned statistical tests. Second, all participants completed the entire survey, which avoided problems with bias from missing data. Third, the survey utilized established measures with known psychometric properties. The scales measuring ACEs, mental distress (Easton et al., 2017; Prochaska et al., 2012) and resilience (Dong et al., 2017; Roy et al., 2011) have been used extensively and have established reliability and validity. Our focus on a predominantly Hispanic, low-income population is also a strength as previous work on ACEs has largely been conducted with Caucasian populations.

One important limitation of this study is that, due to the cross-sectional nature of our data collection, we were not able to infer causation. Future longitudinal research that randomly assigns participants to a resilience promoting intervention or control condition can more rigorously test a causal model of resilience moderating the relation between ACEs and mental distress. A second limitation arises from the complexity of resilience as a construct, which has been defined in different ways and may vary according to culture and environment (Rutten et al., 2013; Ungar \& Liebenberg, 2011; Ungar, 2013). Nevertheless, resilience is thought to be a universal construct and our operationalization is consistent with leading definitions (Ungar, 2013). A third limitation of the study is that findings may not generalize to other regions due to the unique characteristics of this study's population. Finally, a fourth limitation is the exclusive reliance on selfreported survey data, which may artificially inflate the associations found due to a method bias.

\section{Future Implications}

Study findings suggest a need for interventions that develop resilience among individuals exposed to ACEs. One promising example is the program 2 Gen Thrive, which prevents stress and promotes resilience for at-risk low-income families by improving caregiver ability to respond to a child's development including their emotional and behavioral needs (Woods-Jaeger et al., 2018). Further development and testing are needed to identify evidence-based resilience interventions with long-term benefits.

Policies that protect children and prevent abuse are also needed to reduce the incidence of ACEs. Conditional cashtransfer programs, where parents receive financial support on the condition, they participate in programs designed to benefit their children, have been successful in several contexts (Gross et al., 2011). Another promising approach to preventing child abuse and neglect is the CDC's Veto 
Violence initiative, which provides prevention tools, trainings and resources for ACE prevention (CDC, 2019). To enhance monitoring and early detection, there is a need for service providers across settings to assess and address ACEs in terms of mental health. Trainings for physicians, educators, and the community on detecting and addressing ACEs may help in this regard.

\section{Conclusion}

This study identifies resilience as a moderator of the relation between ACEs and mental health. Given the prevalence of ACEs as a public health concern associated with poor mental health (Felitti \& De Anda, 2009), unemployment (Allem et al., 2015), substance abuse (Chandler et al., 2018) and early death (Felitti et al., 1998), resilience has important implications for prevention and health promotion. This study provides the empirical rationale for a call to action to promote resiliency in Hispanic communities, given its centrality in establishing a healthy future for children and adults exposed to adversity.

\section{Declarations}

Conflict of Interest On behalf of all authors, the corresponding author states that there is no conflict of interest.

Open Access This article is licensed under a Creative Commons Attribution 4.0 International License, which permits use, sharing, adaptation, distribution and reproduction in any medium or format, as long as you give appropriate credit to the original author(s) and the source, provide a link to the Creative Commons licence, and indicate if changes were made. The images or other third party material in this article are included in the article's Creative Commons licence, unless indicated otherwise in a credit line to the material. If material is not included in the article's Creative Commons licence and your intended use is not permitted by statutory regulation or exceeds the permitted use, you will need to obtain permission directly from the copyright holder. To view a copy of this licence, visit http://creativecommons.org/licenses/by/4.0/.

\section{References}

Agorastos, A., Pittman, J. O. E., Angkaw, A. C., Nievergelt, C. M., Hansen, C. J., Aversa, L. H., \& Baker, D. G. (2014). The cumulative effect of different childhood trauma types on self-reported symptoms of adult male depression and PTSD, substance abuse and health-related quality of life in a large active-duty military cohort. Journal of Psychiatric Research, 58, 46-54. https://doi. org/10.1016/j.jpsychires.2014.07.014

American Psychological Association. (2020). APA Dictionary of Psychology. Retrieved September 01, 2020, from https://dictionary. apa.org/psychological-distres

Allem, J. P., Soto, D. W., Baezconde-Garbanati, L., \& Unger, J. B. (2015). Adverse childhood experiences and substance use among Hispanic emerging adults in Southern California. Addictive
Behaviors, 50, 199-204. https://doi.org/10.1016/j.addbeh.2015. 06.038

Banyard, V., Hamby, S., \& Grych, J. (2017). Health effects of adverse childhood events: Identifying promising protective factors at the intersection of mental and physical well-being. Child Abuse \& Neglect, 65, 88-98. https://doi.org/10.1016/j.chiabu.2017.01.011

Barrera, I., Sharma, V., \& Aratani, Y. (2019). The Prevalence of Mental Illness and Substance Abuse Among Rural Latino Adults with Multiple Adverse Childhood Experiences in California. Journal of Immigrant \& Minority Health, 21(5), 971-976. https://doi.org/ 10.1007/s10903-018-0811-9

Bellis, M. A., Hardcastle, K., Ford, K., Hughes, K., Ashton, K., Quigg, Z., \& Butler, N. (2017). Does continuous trusted adult support in childhood impart life-course resilience against adverse childhood experiences - a retrospective study on adult health-harming behaviors and mental well-being. BMC Psychiatry, 171-12. https://doi. org/10.1186/s12888-017-1260-Z

Bray, C., \& Swann, C. (2018). Supporting adolescent mental health: Examining the effects of an internet-supported resilience intervention in adolescent soccer players. Frontiers in Psychology, 9. https://doi.org/10.3389/conf.fpsyg.2018.74.00003

Brown, M. J., Thacker, L. R., \& Cohen, S. A. (2013). Association between Adverse Childhood Experiences and Diagnosis of Cancer. PloS One, 8(6), https://doi.org/10.1371/journal.pone.0065524

Caballero, T. M., Johnson, S. B., Buchanan, C. R., \& Decamp, L. R. (2017). Adverse Childhood Experiences Among Hispanic Children in Immigrant Families Versus US-Native Families. Pediatrics, 140(5). https://doi.org/10.1542/peds.2017-0297

Caplan, S., Escobar, J., Paris, M., Alvidrez, J., Dixon, J. K., Desai, M. M., Whittemore, R. (2012). Cultural Influences on Causal Beliefs About Depression Among Latino Immigrants. Journal of Transcultural Nursing, 24(1), 68-77. https://doi.org/10.1177/ 1043659612453745

Center for Disease Control and Prevention CDC. (2019). Injury Prevention \& Control: Division of Violence Prevention. CDC. https:// vetoviolence.cdc.gov/apps/main/home

Chandler, G. E., Kalmakis, K. A., \& Murtha, T. (2018). Screening adults with substance use disorder for adverse childhood experiences. Journal of Addictions Nursing, 29(3), 172-178. https://doi. org/10.1097/JAN.0000000000000233

Chang, X., Jiang, X., Mkandarwire, T., \& Shen, M. (2019). Associations between adverse childhood experiences and health outcomes in adults aged 18-59 years. PLoS One, 14(2), 1-11. https://doi. org/10.1371/journal.pone.0211850

Chavez-Dueñas, N. Y., Adames, H. Y., Perez-Chavez, J. G., \& Salas, S. P. (2019). Healing ethno-racial trauma in Latinx immigrant communities: Cultivating hope, resistance, and action. American Psychologist, 74(1), 49-62. https://doi.org/10.1037/amp000028

CIERP. (2018). University of Texas at El Paso. The Center for Institutional Evaluation, Research and Planning at UTEP. https://doi. org/10.1002/ir.303

Cohen. (1988). Statistical power analysis for the behavioral sciences (2nd ed.). L. Erlbaum Associates. https://doi.org/10.4324/9780203771587

Connor, K. M., \& Davidson, J. R. (2003). Development of a new resilience scale: The Connor Davidson Resilience Scale (CD-RISC). Depression and Anxiety, 18(2), 76-82. https://doi.org/10.1002/da. 10113

Dong, X., Li, G., Liu, C., Kong, L., Fang, Y., Kang, X., \& Li, P. (2017). The mediating role of resilience in the relationship between social support and posttraumatic growth among colorectal cancer survivors with permanent intestinal ostomies: A structural equation model analysis. European Journal of Oncology Nursing: the Official Journal of European Oncology Nursing Society, 29, 47-52. https://doi.org/10.1016/j.ejon.2017.04.007

Easton, S. D., Safadi, N. S., Wang, Y., Hasson, R. G., III., Wang, Y., \& Hasson, R. G., 3rd. (2017). The Kessler psychological distress scale: 
Translation and validation of an Arabic version. Health \& Quality of Life Outcomes, 15, 1-7. https://doi.org/10.1186/s12955-017-0783-9

Edwards, V. J., Holden, G. W., Felitti, V. J., \& Anda, R. F. (2003). Relationship Between Multiple Forms of Childhood Maltreatment and Adult Mental Health in Community Respondents: Results From the Adverse Childhood Experience Study. American Journal of Psychiatry, 160(8), 1453. https://doi.org/10.1176/appi.ajp. 160.8.1453

Elkins, J., Miller, K. M., Briggs, H. E., Kim, I., Mowbray, O., \& Orellana, E. R. (2019). Associations between Adverse Childhood Experiences, Major Depressive Episode and Chronic Physical Health in Adolescents: Moderation of Race/Ethnicity. Social Work in Public Health, 34(5), 444-456. https://doi.org/10.1080/19371918.2019.1617216

Felitti, V. J., Anda, R. F., Nordenberg, D., Williamson, D. F., Spitz, A. M., Edwards, V., \& Marks, J. S. (1998). Relationship of Childhood Abuse and Household Dysfunction to Many of the Leading Causes of Death in Adults. American Journal of Preventive Medicine, 14(4), 245-258. https://doi.org/10.1016/s0749-3797(98) 00017-8

Felitti, V., \& Anda, R. (2009). The relationship of adverse childhood experiences to adult medical disease, psychiatric disorders, and sexual behavior: Implications for healthcare. In R. Lanius \& E. Vermetten (Eds.), The hidden epidemic: The impact of early life trauma on health and disease. Cambridge: Cambridge University Press.

Forbes, S., \& Fikretoglu, D. (2018). Building resilience: The conceptual basis and research evidence for resilience training programs. Review of General Psychology. https://doi.org/10.1037/gpr0000152

Gilbert, L. K., Breiding, M. J., Merrick, M. T., Thompson, W. W., Ford, D. C., Dhingra, S. S., \& Parks, S. E. (2015). Childhood adversity and adults chronic disease: An update from ten states and the District of Columbia, 2010. American Journal of Preventative Medicine, 48(3), 345-434. https://doi.org/10.1016/j.amepre.2014. 09.006

Gross, D., Johnson, T., Ridge, A., Garvey, C., Julion, W., Treysman, A. B., \& Fogg, L. (2011). Cost-effectiveness of childcare discounts on parent participation in preventive parent training in low-income communities. The Journal of Primary Prevention, 32, 283-298. https://doi.org/10.1007/s10935-011-0255-7

Hamby, S., Grych, J., \& Banyard, V. (2018). Resilience portfolios and poly-strengths: Identifying protective factors associated with thriving after adversity. Psychology of Violence, 8(2), 172-183. https://doi.org/10.1037/vio000013

Hammarström, A., Westerlund, H., Kirves, K., Nygren, K., Virtanen, P., \& Hägglöf, B. (2016). Addressing challenges of validity and internal consistency of mental health measures in a 27- year longitudinal cohort study - the Northern Swedish Cohort study. BMC Medical Research Methodology, 161-9. https://doi.org/10.1186/ s12874-015-0099-6

Johnson, S. B., Riley, A. W., Granger, D. A., \& Riis, J. (2013). The science of early life toxic stress for pediatric practice and advocacy. Pediatrics, 131, 319-327. https://doi.org/10.1542/peds.2012-0469

Karatekin, C. (2018). Adverse Childhood Experiences (ACEs), Stress and Mental Health in College Students. Stress \& Health: Journal of the International Society for the Investigation of Stress, 34(1), 36-45. https://doi.org/10.1002/smi.2761

Katiria Perez, G., \& Cruess, D. (2014). The impact of familism on physical and mental health among Hispanics in the United States. Health Psychology Review, 8(1), 95-127. https://doi.org/ 10.1080/17437199.2011.56993

Kessler, R. C., Barker, P. R., Colpe, L. J., Epstein, J. F., Gfroerer, J. C., Hiripi, E., et al. (2003). Screening for serious mental illness in the general population. Archives of General Psychiatry, 60(2), 184-189. https://doi.org/10.1001/archpsyc.60.2.184

LaBrenz, C. A., Panisch, L. S., Lawson, J., Borcyk, A. L., Gerlach, B., Tennant, P. S., Nulu, S., \& Faulkner, M. (2020). Adverse Childhood
Experiences and Outcomes among At-Risk Spanish-Speaking Latino Families. Journal of Child \& Family Studies, 29(5), 12211235. https://doi.org/10.1007/s10826-019-01589=

Logan-Greene, P., Green, S., Nurius, P. S., \& Longhi, D. (2014). Distinct contributions of adverse childhood experiences and resilience resources: A cohort analysis of adult physical and mental health. Social Work in Health Care, 53(8), 776-797. https://doi.org/10.1080/ 00981389.2014.944251

Mackay, B. A., Shochet, I. M., \& Orr, J. A. (2017). A Pilot Randomised Controlled Trial of a School-Based Resilience Intervention to Prevent Depressive Symptoms for Young Adolescents with Autism Spectrum Disorder: A Mixed Methods Analysis. Journal of Autism and Developmental Disorders, 47(11), 3458-3478. https:// doi.org/10.1007/s10803-017-3263-5

Martel, M. M., Nigg, J. T., Wong, M. M., Fitzgerald, H. E., Jester, J. M., Puttler, L. I., Glass, J. M., Adams, K. M., \& Zucker, R. A. (2007). Childhood and adolescent resiliency, regulation, and executive functioning in relation to adolescent problems and competence in a high-risk sample. Development and Psychopathology, 19(2), 541-563. https://doi.org/10.1017/S0954579407070265

Martín-Blanco, A., Ferrer, M., Soler, J., Arranz, M., Vega, D., Calvo, N., \& Pascual, J. (2016). The role of hypothalamus-pituitary-adrenal genes and childhood trauma in borderline personality disorder. European Archives of Psychiatry \& Clinical Neuroscience, 266(4), 307-316. https://doi.org/10.1007/s00406-015-0612-2

Merrick, M. T., Ford, D. C., Ports, K. A., \& Guinn, A. S. (2018). Prevalence of Adverse Childhood Experiences From the 2011-2014 Behavioral Risk Factor Surveillance System in 23 States. JAMA Pediatrics, 172(11), 1038-1044. https://doi.org/10.1001/jamapediatrics.2018.253

Mersky, J., Topitzes, J., \& Reynolds, A. (2013). Impacts of adverse childhood experiences on health, mental health, and substance use in early adulthood: A cohort study of an urban, minority sample in the U.S. Child Abuse \& Neglect, 37(11), 917-925. https://doi. org/10.1016/j.chiabu.2013.07.011

Motrico, E., Moreno-Küstner, B., de Dios Luna, J., Torres-González, F., King, M., Nazareth, I., \& Ángel Bellón, J. (2013). Psychometric properties of the List of Threatening Experiences-LTE and its association with psychosocial factors and mental disorders according to different scoring methods. Journal of Affective Disorders, 150(3), 931-940. https://doi.org/10.1016/j.jad.2013.05.017

Navalta, C. P., McGee, L., \& Underwood, J. (2018). Adverse Childhood Experiences, Brain Development, and Mental Health: A Call for Neurocounseling. Journal of Mental Health Counseling, 40(3), 266-278. https://doi.org/10.17744/mehc.40.3.07

Newcomb, M. D., Locke, T. F., \& Goodyear, R. K. (2003). Childhood Experiences and Psychosocial Influences on HIV Risk Among Adolescent Latinas in Southern California. Cultural Diversity \& Ethnic Minority Psychology, 9(3), 219-235. https://doi.org/10. 1037/1099-9809.9.3.219

Nurius, P., LaValley, K., \& Kim, M.-H. (2020a). Victimization, Poverty, and Resilience Resources Stress Process Considerations for Adolescent Mental Health. School Mental Health, 12(1), 124-135. https://doi.org/10.1007/s12310-019-09335-z

Liu, S. R., Kia-Keating, M., Nylund-Gibson, K., \& Barnett, M. L. (2020). Co-Occurring Youth Profiles of Adverse Childhood Experiences and Protective Factors: Associations with Health, Resilience, and Racial Disparities. American Journal of Community Psychology, 65(1-2), 173-186. https://doi.org/10.1002/ ajcp. 12387

Labrenz, C. A., Panisch, L. S., Lawson, J., Borcyk, A. L., Gerlach, B., Tennant, P. S., Faulkner, M. (2019). Adverse Childhood Experiences and Outcomes among At-Risk Spanish-Speaking Latino Families. Journal of Child and Family Studies, 29(5), 1221-1235. https://doi.org/10.1007/s10826-019-01589-0

Nurius, P., LaValley, K., \& Kim, M.-H. (2020b). Victimization, Poverty, and Resilience Resources: Stress Process Considerations for 
Adolescent Mental Health. School Mental Health, 12(1), 124-135. https://doi.org/10.1007/s12310-019-09335-z

Poole, J. C., Dobson, K. S., \& Pusch, D. (2017). Childhood adversity and adult depression: The protective role of psychological resilience. Child Abuse \& Neglect, 64, 89-100. https://doi.org/ 10.1016/j.chiabu.2016.12.012

Prince, M., Patel, V., Saxena, S., Maj, M., Maselko, J., Phillips, M., \& Rahman, A. (2016). No health without mental health. Mental Illness, 8(2). https://doi.org/10.4081/mi.2016.6609

Prochaska, J. J., Sung, H., Max, W., Shi, Y., \& Ong, M. (2012). Validity study of the K6 scale as a measure of moderate mental distress based on mental health treatment need and utilization. International Journal of Methods in Psychiatric Research, 21(2), 88-97. https://doi.org/10.1002/mpr.1349

Purewal, S. K., Marques, S. S., Koita, K., \& Bucci, M. (2016). Assessing the integration of the Center for Youth Wellness Adverse Childhood Experiences Questionnaire (CYW ACEQ) in a pediatric primary care setting. Journal of Adolescent Health, 58(2), S47-S47. https://doi.org/10.1016/j.jadohealth. 2015.10.106

Manyema, M., Norris, S. A., \& Richter, L. M. (2018). Stress begets stress: the association of adverse childhood experiences with psychological distress in the presence of adult life stress. BMC Public Health, 18(1), 835-835. https://doi.org/10.1186/s12889-018-5767-0

Merino, R., \& J., Lluch-Canut, M. T., Casas, I., Sanromà-Ortíz, M., FerréGrau, C., Sequeira, C., \& Puig-Llobet, M. (2017). Reliability and validity of the Positive Mental Health Questionnaire in a sample of Spanish university students. Journal of Psychiatric \& Mental Health Nursing, 24(2/3), 123-133. https://doi.org/10.1111/jpm.12358

Robottom, B. J., Gruber-Baldini, A. L., Anderson, K. E., Reich, S. G., Fishman, P. S., Weiner, W. J., \& Shulman, L. M. (2011). What determines resilience in patients with Parkinson's disease? Parkinsonism \& Related Disorders, 18(2), 174-177. https://doi.org/10. 1016/j.parkreldis.2011.09.021

Rojas-Flores, L., Clements, M. L., Koo, J. H., \& London, J. (2017). Trauma and psychological distress in Latino citizen children following parental detention and deportation. Psychological Trauma: Theory, Research, Practice, and Policy, 9(3), 352-361. https://doi. org/10.1037/tra0000177

Roy, A., Carli, V., \& Sarchiapone, M. (2011). Resilience mitigates the suicide risk associated with childhood trauma. Journal of Affective Disorders, 133(3), 591-594. https://doi.org/10.1016/j.jad.2011. 05.006

Rutten, B. P., Hammels, C., Geschwind, N., Menne-Lothmann, C., Pishva, E., Schruers, K., van den Hove, D., Kenis, G., van Os, J., \& Wichers, M. (2013). Resilience in mental health: linking psychological and neurobiological perspectives. Acta Psychiatrica Scandinavica, 128(1), 3-20. https://doi.org/10.1111/acps.12095

Sciaraffa, M. A., Zeanah, P. D., \& Zeanah, C. H. (2018). Understanding and promoting resilience in the context of adverse childhood experiences. Early Childhood Education Journal, 46(3), 343-353. https://doi.org/10.1007/s10643-017-0869-3

Soler Sánchez, M. I., Meseguer de Pedro, M., \& García Izquierdo, M. (2016). Propiedades psicométricas de la versión española de la escala de resiliencia de 10 ítems de Connor-Davidson (CD-RISC 10) en una muestra multiocupacional. Revista latinoamericana de psicología, 48(3), 159-166. https://doi.org/10.1016/j.rlp.2015. 09.002

Spencer-Hwang, R., Torres, X., Valladares, J., Pasco-Rubio, M., Dougherty, M., \& Kim, W. (2018). Adverse Childhood Experiences among a Community of Resilient Centenarians and Seniors: Implications for a Chronic Disease Prevention Framework. Permanente Journal, 22(2), 33-41. https://doi.org/10.7812/TPP/ 17-146

Ungar, M., \& Liebenberg, L. (2011). Assessing Resilience Across Cultures Using Mixed Methods: Construction of the Child and Youth Resilience Measure. Journal of Mixed Methods Research, 5(2), 126-149. https://doi.org/10.1177/1558689811400607

Ungar, M. (2013). Resilience, Trauma, Context, and Culture. Trauma, Violence \& Abuse, 14(3), 255-266. https://doi.org/10.1177/15248 38013487805

Venta, A., Bailey, C., Muñoz, C., Godinez, E., Colin, Y., Arreola, A., Abate, A., Camins, J., Rivas, M., \& Lawlace, S. (2019). Contribution of schools to mental health and resilience in recently immigrated youth. School Psychology, 34(2), 138-147. https:// doi.org/10.1037/spq0000271

Villalobos, B. T., \& Bridges, A. J. (2018). Prevalence of substance use disorders among Latinos in the United States: An empirical review update. Journal of Latina/o Psychology, 6(3), 204-219. https:// doi.org/10.1037/lat0000097

Woods-Jaeger, B. A., Sexton, C. C., Gardner, B., Siedlik, E., Slagel, L., Tezza, V., \& O'Malley, D. (2018). Development, feasibility, and refinement of a toxic stress prevention research program. Journal of Child and Family Studies, 27(11), 3531-3543. https://doi.org/ 10.1007/s10826-018-1178-1

World Health Organization (WHO). (2004). Promoting mental health: concepts, emerging evidence, practice (Summary Report) Geneva: World Health Organization. https://apps.who.int/iris/bitstream/ handle/10665/42940/9241591595.pdf

Zetino, Y. L., Galicia, B. E., \& Venta, A. (2020). Adverse Childhood Experiences, Resilience, and Emotional Problems in Latinx Immigrant Youth. Psychiatry Research, 293, 113450-113450. https:// doi.org/10.1016/j.psychres.2020.113450

Zhang, W., Hong, S., Takeuchi, D. T., \& Mossakowski, K. N. (2012). Limited English proficiency and psychological distress among Latinos and Asian Americans. Social Science \& Medicine, 75(6), 1006-1014. https://doi.org/10.1016/j.socscimed.2012.05.012

Publisher's Note Springer Nature remains neutral with regard to jurisdictional claims in published maps and institutional affiliations. 